\title{
"Con los pobres de la tierra quiero yo mi suerte echar...": la figura del intelectual- lumpen en las obras de Guillermo Rosales y Pedro Juan Gutiérrez
}

\author{
"With the Poor People of the Earth I want to Cast my \\ Luck...": The Figure of the Lumpen-Intellectual in the \\ Works of Guillermo Rosales and Pedro Juan Gutiérrez
}

\begin{abstract}
Resumen
En este artículo, se analizan la novela Boarding home (1987) y la colección de cuentos Trilogía sucia de La Habana (1998) escritas, respectivamente, por los cubanos Guillermo Rosales y Pedro Juan Gutiérrez. Estas obras comparten una característica esencial, dado que nos presentan relatos en primera persona cuyos artífices son creadores literarios que, tras una sucesión dramática de acontecimientos, se han convertido en marginados. Así, los discursos de estos narradores se construyen desde el interior de una realidad signada por las carencias materiales de todo género y la exclusión con respecto a los modelos que rigen el orden social. Partiendo de aquí, me propongo estudiar las actitudes y las trayectorias de ambos personajes, muchas veces coincidentes entre sí, con la intención de establecer los rasgos que puede asumir la figura del intelectual en los territorios excéntricos. Para cumplir con este objetivo, me serviré de varios apoyos teóricos, entre los que destacan la noción de intelligentsia paria forjada por Max Weber, el concepto de infrapolítica desarrollado por James C. Scott y las ideas acerca del lumpen que plantean Karl Marx y Friedrich Engels.
\end{abstract}

Palabras claves Pobreza;, lumpen; estructuras de poder; cultura de los márgenes; intelligentsia paria. 


\begin{abstract}
This paper presents the analysis of the novel Boarding Home (1987) and the short stories collection Trilogía sucia de La Habana (1998), respectively written by the Cuban writers Guillermo Rosales and Pedro Juan Gutiérrez. These works share an essential characteristic: their authors, who narrate using the first person, became outsiders after a dramatic succession of events. Consequently, they build their discourse from an inner reality forged by all kind of material lack, as well as the exclusion from the models ruling the social order. Taking this as a starting point, the paper studies the often-similar attitudes and careers of both characters in order to establish those features the figure of the intellectual could assume in eccentric domains. Such objective will be achieved by means of different kinds of theoretical support, mainly: the pariah intelligentsia by Max Weber, the infrapolitics concept by James C. Scott and the ideas on lumpen by Karl Marx and Friedrich Engels.
\end{abstract}

Keywords

Poverty, lumpen, power structures, marginal culture, pariah intelligentsia.

"No toleraremos [...] que aquellos por los cuales debemos preocuparnos, y que se espera que lleguen a ser hombres de bien, $[\ldots]$ imiten a $[\ldots]$ esclavas o a esclavos, al menos realizando actos serviles. [...] Ni que representen a hombres viles y cobardes [...]. Creo también que no se los debe acostumbrar a imitar, ni en palabras ni en actos, a los que enloquecen".

(Platón. República)

En Sociología de la religión, Max Weber cuestiona algunas ideas acerca de la intelectualidad que, históricamente, han gozado de un predicamento innegable. Concretamente, se refiere a la visión de este colectivo como una entidad homogénea, constituida por individuos que, en virtud de sus privilegios, acceden a las esferas más altas del conocimiento, desarrollando un trabajo que promueve el avance de la cultura en todos los terrenos. Frente a esta concepción, el filósofo alemán sostiene que, dentro de lo que él llama intelligentsia, conviven dos categorías distintas. Sin duda, cabe hablar de un "intelectualismo elitista" cuyos representantes, adscritos a las "clases [...] social y económicamente acomodadas", se forman y actúan en marcos institucionales (Weber 184); pero también existe una 
facción paralela a esta, la del intelectualismo "paria" o "semiproletario", en la que se congregan los tipos más variados, desde "pequeños funcionarios y pequeños beneficiarios de cualquier época", a "maestros elementales [...] cantores vagabundos, lectores, narradores, recitadores" (Weber 184).

El autor describe una especie de cofradía que se caracteriza por la heterogeneidad de sus miembros, si bien considera que estos comparten un rasgo clave, dado que los presenta como "gentes al borde del mínimo de la existencia" (Weber 184). Nos hallamos, pues, ante sujetos que se relacionan con la cultura de una forma singular, marcada por el hecho de pertenecer a los grupos socioeconómicos menos favorecidos. Esta circunstancia se torna fundamental desde el momento en que permite asumir una posición determinada con respecto a las normas de vida y pensamiento que dictan los poderes establecidos:

En la medida en que se trata de intelectualismo "paria" [...] su intensidad deriva de que los estratos situados fuera o en el extremo inferior de la jerarquía social se encuentran en cierta medida en el punto arquimediano frente a las convenciones sociales, tanto en lo que toca al orden externo como a las opiniones comunes. Son capaces, por tanto, de un parecer sobre el "sentido" del cosmos originalmente no determinado por esas convenciones. (185)

Por su condición marginal, la intelligentsia paria no siempre reconoce como propios los valores que rigen una sociedad; de ahí que cuente con la libertad y la independencia necesarias para criticar o subvertir esos principios, cuando no para reemplazarlos por otros. Por ello, sus acciones engendran ideas, discursos y códigos simbólicos que no solo constituyen una alternativa a la cultura oficial, sino que pueden llegar a desestabilizar los cimientos de esta o, incluso, a transformarla.

Weber emplea los argumentos resumidos para efectuar un estudio de las creencias religiosas, ámbito en el que, a su juicio, las aportaciones de la intelligentsia paria se han revelado como un importante motor de cambio. Sin 
embargo, las teorías del alemán resultan lo bastante sugestivas como para ampliar el marco de reflexión en que fueron creadas, de tal modo que permitan enriquecer el análisis del papel que desempeña y los sentidos que adquiere la cultura en los variados territorios donde se radican quienes, por causas también diversas, quedan abocados a la marginalidad.

Precisamente de estos últimos temas se ocupa el antropólogo estadounidense James C. Scott en Los dominados y el arte de la resistencia: discursos ocultos, un ensayo donde, no por casualidad, nos encontramos con la noción de intelligentsia paria que propone Weber. Este y otros conceptos sirven para articular la tesis de que, a menudo, los colectivos subalternos desafían el orden social mediante estrategias que no llaman la atención de los poderes establecidos, pues saben que los actos públicos encaminados a cuestionar el sistema podrían acarrear consecuencias muy graves para ellos. A partir de aquí, Scott postula que las sublevaciones encubiertas de estos grupos se materializan, sobre todo, en el plano simbólico, a través de productos culturales que contravienen las pautas morales e ideológicas de los opresores.

Esta premisa conduce a subrayar la relevancia adquirida por quienes elaboran y propagan unos discursos capaces de constituirse en herramientas de lucha y reivindicación para los desclasados; es decir, por los sujetos que conforman una intelectualidad en el seno de los espacios marginales. El trabajo de estos individuos no tiene por qué inspirar formas abiertas de rebelión, pero alimenta un espíritu subversivo que, a veces, sí logra engendrar resultados palpables, al convertirse en la base de iniciativas y procesos que trastocan algunos fundamentos de la sociedad. Por ello, Scott mantiene que la actividad llevada a cabo por el intelectualismo paria debe catalogarse como "infrapolítica".

Entre los diferentes ejemplos que ofrece el autor para ilustrar sus argumentos comentaré un par de casos, ambos extraídos de la Edad Media, que me parecen especialmente significativos: la subcultura carnavalesca, difundida por "artistas itinerantes de todo tipo", y las interpretaciones heréticas o heterodoxas del cristianismo fraguadas por "el bajo clero renegado, $[\ldots]$ los supuestos profetas, los 
CATEDRAL TOMADA: Revista de crítica literaria latinoamericana / Journal of Latin American Literary Criticism

“Con los pobres de la tierra quiero yo mi suerte echar...": la figura del intelectual-lumpen en las obras de Guillermo Rosales y Pedro Juan Gutiérrez

peregrinos, las sectas y ordenes monásticas marginales, los mendicantes, etcétera" (Scott 153).

En un principio, las instituciones rectoras de la sociedad medieval no consideraron que estos dos fenómenos pudieran suponer una amenaza grave para el orden establecido. De esta manera, asumieron que las distintas expresiones de lo carnavalesco constituían simples válvulas de escape cuya existencia resultaba tolerable. A su vez, los impulsores de las heterodoxias religiosas se presentaban ante los ojos de las autoridades eclesiásticas bien como lunáticos bien como integrantes de minorías relegadas a un segundo plano; es decir, como individuos fáciles de eliminar o de reprimir en cualquiera de los casos.

Sin embargo, estas dos manifestaciones de la infrapolítica acabaron generando resultados tan ostensibles como decisivos. Así, Scott apunta que numerosas "rebeliones de esclavos, de campesinos y de siervos empezaron precisamente durante [...] fiestas periódicas" como el carnaval pues, aunque de un modo en apariencia lúdico e intrascendente, esta clase de actos subrayaba las injusticias generadas por el sistema y, en consecuencia, infundía en los marginados un deseo de alzarse contra el mismo (221) ${ }^{1}$. Por lo que se refiere a los discursos iconoclastas acerca del cristianismo, basta recordar que se convirtieron en el sustrato de dos procesos tan importantes como la Reforma y la Contrarreforma para comprender el alcance de su condición transgresora ${ }^{2}$.

Tanto las aportaciones de Weber como las de Scott me permiten fundamentar una de las tesis centrales que plantearé en este artículo y que cabe resumir de la siguiente forma: la figura del intelectual puede radicarse en los espacios marginales, ámbitos donde adquiere unos rasgos propios y actúa como portavoz o artífice de una cultura paralela a la oficial. Sin embargo, todavía debo

\footnotetext{
${ }^{1}$ Este razonamiento puede complementarse con las teorías que propone Mijail Bajtin en su conocido trabajo acerca del carnaval y el grotesco: La cultura popular en la Edad Media y en el Renacimiento (1990).

${ }^{2}$ En todo lo que concierne a este asunto, resulta de consulta obligada el volumen Herejías y sociedades en la Europa preindustrial (Siglos XI-XVIII): comunicaciones y debates del Coloquio de Royaumont, coordinado por Jacques Le Goff (1987).
} 
añadir otra idea más a las presentadas ya que, tal vez, lo expuesto hasta ahora ha generado la impresión de que la intelligentsia paria y su correlato elitista se ubican en territorios separados y ajenos entre sí. Esta diferenciación categórica no llega a producirse dado que, como señala Weber, ambos grupos entran en contacto por medio de "transiciones sucesivas" (184); o, dicho de otra forma, a través de movimientos que se dan en varias direcciones.

Uno de estos posibles desplazamientos tiene lugar cuando los representantes de la intelectualidad canónica adoptan la perspectiva del marginado, fórmula que, por ejemplo, resulta propia de la literatura picaresca, sobre todo en el caso de aquellas obras que se valen de la narración en primera persona. Gracias a este recurso, el autor culto asume la voz de un desclasado que, mientras refiere su historia personal, lleva a cabo dos acciones importantes: por un lado, describe con exactitud las normas de conducta y los esquemas de pensamiento que se imponen en los estratos menos favorecidos de la sociedad; $\mathrm{y}$, al tiempo, efectúa un análisis crítico de esta última, poniendo el acento en sus fallos y carencias. Por todo lo dicho, cabe afirmar que este tipo se constituye en un miembro de la intelligentsia paria, pues aparece como el creador de un producto cultural, su relato, que no solo confiere visibilidad al mundo de los colectivos oprimidos y subalternos: también adquiere una indudable condición subversiva al poner en tela de juicio el orden establecido.

A lo largo de la historia, se han dado numerosos fenómenos similares al que observamos en la picaresca; es decir, muchos intelectuales al uso han hecho suyos códigos y estrategias pertenecientes a la cultura paralela que se forja en los territorios excéntricos. Una muestra de ello nos la ofrecen los representantes de las Vanguardias que, en su búsqueda continua de formas nuevas y transgresoras, reivindican las creaciones artísticas ejecutadas por individuos marginados, tales como enfermos psiquiátricos, sirviéndose, además, de técnicas e imágenes presentes en las mismas. Estas prácticas se encuentran en la base del concepto de Art Brut, acuñado por Jean Dubuffet en 1945 para designar "producciones" que ostentan "un carácter espontáneo y muy inventivo así como poco endeudado con 
CATEDRAL TomAda: Revista de crítica literaria latinoamericana / Journal of Latin American Literary Criticism

"Con los pobres de la tierra quiero yo mi suerte echar...": la figura del intelectual-lumpen en las obras de Guillermo Rosales y Pedro Juan Gutiérrez

las frivolidades culturales y que tienen como autores a personas oscuras y extrañas a los medios profesionales" (280). El francés considera que las manifestaciones heterodoxas del arte gestadas por outsiders revelan unas cualidades propias, de modo que sus ideas, aún vigentes en nuestros días, pueden conectarse con la noción de intelligentsia paria que aporta Weber ${ }^{3}$.

Los ejemplos que acabo de comentar implican un reconocimiento e, incluso, una defensa del otro, pero no el traslado completo a sus espacios. Sin embargo, esta última posibilidad también resulta factible y, de hecho, se plantea en dos obras que intentaré analizar tomando como base las consideraciones efectuadas hasta el momento: Boarding home (1987) y Trilogía sucia de La Habana (1998), novela y colección de cuentos escritas, respectivamente, por los cubanos Guillermo Rosales (1946-1993) y Pedro Juan Gutiérrez (1950).

Los narradores y protagonistas de ambos textos, William Figueras en Boarding home y Pedro Juan en Trilogía, son autores literarios que se ven condenados al ostracismo por unas estructuras concretas de poder. A causa de ello, han de radicarse en ámbitos regidos por la miseria y la abyección, donde convivirán con desclasados que soportan estigmas diversos: pobreza, incultura, enfermedades mentales, características tachadas de anómalas e, incluso, de monstruosas... Los dos personajes, además, optan por aclimatarse a estas nuevas circunstancias, de tal modo que redefinen su identidad a partir de una plena integración en las orillas del sistema. Con esto, forjan relatos en primera persona que logran llevar a la literatura el mundo de los parias como una realidad no ajena, sino conocida y experimentada desde dentro. En este sentido, Amir Valle señala una característica de Pedro Juan que, igualmente, puede atribuirse al protagonista de Boarding home: el talento para describir la marginalidad "desde la participación” y "la pertenencia” (n.p.).

Estas figuras revelan parecidos aún más evidentes y numerosos cuando las examinamos a fondo. Pedro Juan y Figueras aparecen como tipos hundidos en una

\footnotetext{
${ }^{3}$ Para un análisis más exhaustivo del Art Brut véanse El hombre de la calle ante la obra de arte, del propio Dubuffet (1992); Outsider Art, de Roger Cardinal (1972); L'art brut, de Michel Thévoz (1995) y En torno al art brut, volumen editado por Serge Fauchereau (2007).
} 
situación de precariedad e ignominia motivada por acontecimientos que ellos mismos se ocupan de consignar. Estos hechos, que además de repercutir en su vida privada afectan a la evolución de su trayectoria como intelectuales, se identifican con procesos y fenómenos que han marcado la historia reciente de Cuba. Debido a ello, y aunque diferenciados por algunos matices, los caminos que recorren ambos se tornan paralelos.

Para empezar, los dos subrayan la influencia que ejercieron determinadas prácticas del gobierno socialista en el desarrollo de sus respectivas carreras como intelectuales. Aquí conviene recordar que, tal como indica Ana Belén Martín Sevillano, "el control de los órganos y esferas culturales (escuelas, universidades, medios de comunicación, editoras) y [...] de los propios agentes era la base del establecimiento de la Revolución", pues se consideraba que esta debía fundamentarse en "un saber" directamente vinculado con "el sistema político" (36). Por ello, se adoptaron medidas encaminadas a la creación de una intelligentsia militante, cuya tarea consistiría en reivindicar tanto el discurso como las iniciativas del estado para favorecer el surgimiento de lo que Ernesto Guevara llamó "conciencias revolucionarias"4. Se trataba, entonces, de congregar a los intelectuales en un grupo compacto, homogéneo y dirigido por un mandato que impuso Fidel Castro en el Primer Congreso Nacional de Educación y Cultura (1971): "Dentro de la Revolución, todo; contra la Revolución, nada. Contra la Revolución nada, porque la Revolución tiene también sus derechos y el primer derecho de la Revolución es el derecho a existir y frente al derecho de la Revolución de ser y de existir, nadie" (14).

De acuerdo con estas normas, se diseñaron recursos concebidos para supervisar el trabajo que realizaban los productores de cultura y los canales que permitían la difusión del mismo. Con el paso del tiempo, estos mecanismos han

\footnotetext{
${ }^{4}$ Este concepto responde a una idea fundamental para el Che, quien se mostró convencido de que la auténtica revolución socialista debía cambiar tanto las pautas económicas vigentes como las estructuras mentales de los individuos. Para conocer a fondo sus planteamientos, que sin duda inspiraron la política cultural a la que me estoy refiriendo, puede consultarse El socialismo y el hombre nuevo (2003), recopilación de textos, discursos y conferencias del guerrillero argentino.
} 
CATEDRAL Tomada: Revista de crítica literaria latinoamericana / Journal of Latin American Literary Criticism

"Con los pobres de la tierra quiero yo mi suerte echar...": la figura del intelectual-lumpen en las obras de Guillermo Rosales y Pedro Juan Gutiérrez

experimentado cambios que les han conferido diversos grados de flexibilidad; pero, sin duda, han determinado que un buen número de intelectuales encontrara serias dificultades a la hora de ejercer su profesión.

A lo largo de Trilogía, Pedro Juan va revelando cómo se ha visto afectado por las cuestiones recién expuestas. Por ejemplo, en el texto titulado "El recuerdo de la ternura", comenta lo siguiente: "Yo me ganaba la vida haciendo un periodismo malsano y cobarde, lleno de concesiones, donde me censuraban todo, y eso me angustiaba porque cada día me sentía más como un mercenario miserable, con mi ración diaria de patadas por el culo" (Gutiérrez 13). Más tarde, en el cuento "Un día yo estaba agotado", explica los motivos de esta situación y la forma en que reaccionó ante ella:

Aquí hace treinta y cinco años que no conviene hablar de nada desagradable ni preocupante [...]. Todo debe estar bien. Una sociedad modelo no puede tener crímenes ni cosas feas. [...] Si no tienes toda la información no puedes pensar, ni decidir, ni opinar. Te conviertes en un tonto capaz de creer cualquier cosa. Por eso yo estaba tan desilusionado con el periodismo y comencé a escribir unos relatos muy crudos. En tiempos tan desgarradores no se puede escribir suavemente. [...] Escribo para pinchar un poco y obligar a otros a oler la mierda. Hay que bajar el hocico al piso y oler la mierda. Así aterrorizo a los cobardes y jodo a los que gustan amordazar a quienes podemos hablar. (Gutiérrez 85)

La insubordinación del personaje acarrea una consecuencia terrible a la que él mismo se refiere cuando apunta que lo "botaron del periodismo porque cada día era más visceral" (Gutiérrez 14). Perder el medio de vida conlleva un acercamiento a la marginalidad; pero, además, esta grave circunstancia personal coincide con un proceso histórico también funesto como es la crisis económica que golpeó Cuba durante los años 90. Precisamente, el colapso financiero y sus repercusiones conforman el marco donde transcurren muchos de los textos que componen 
Trilogía. Así, el narrador y protagonista de estos no solo muestra las condiciones dramáticas que soportan los cubanos ante la incapacidad del gobierno para combatir el avance de la miseria; también, y sobre todo, describe la feroz lucha por la subsistencia diaria en que debe embarcarse junto a la mayoría de sus compatriotas, una batalla sin cuartel que exige renunciar al civismo, a los dictados morales e, incluso, a la propia humanidad ${ }^{5}$. Habla, entonces, de unos comportamientos que, habitualmente, no se atribuyen a los ciudadanos convencionales, sino a quienes ocupan las periferias del sistema. Por ello, descubrimos que la necesidad imperiosa de asumir estas conductas da lugar a su plena transformación en un paria.

Al igual que Pedro Juan, Figueras sufre el rechazo de los órganos culturales instituidos por el socialismo cubano, experiencia que nos relata de la siguiente manera:

Hace veinte años terminé una novela en Cuba que contaba la historia de un romance entre un comunista y una burguesa, y acababa con el suicidio de ambos. La novela nunca se publicó y mi romance nunca fue conocido por el gran público. Los especialistas literarios del gobierno dijeron que mi novela era morbosa, pornográfica, y también irreverente, pues trataba al Partido Comunista con dureza. Luego me volví loco. Empecé a ver diablos en las paredes, comencé a oír voces que me insultaban y dejé de escribir. Lo que me salía era espuma de perro rabioso. (Rosales 13-14)

El narrador parece conectar el varapalo que le infligen los "especialistas literarios del gobierno" con la aparición de un trastorno mental que, como veremos enseguida, contribuirá a hundirlo en la marginalidad. Por tanto, su caso resulta equiparable al de Pedro Juan ya que, para ambos, la confrontación con el sistema

${ }^{5}$ El personaje expone esta realidad de un modo ejemplar en el siguiente pasaje del cuento "Salíamos de las jaulas": "Hacíamos nuestra entrada en la jungla. Así, a patadas por el culo. Todos salíamos de las jaulas $[\ldots]$ atrofiados $[\ldots]$ y temerosos. No teníamos ni idea de cómo era la batalla en la jungla. Pero había que hacerlo. Estuvimos encerrados treinta y cinco años en las jaulas del Zoo. Nos daban alguna comidita y alguna medicina, pero ni idea de cómo era todo más allá de los barrotes. Y de pronto hay que saltar a la selva" (Gutiérrez 139). 
establecido da origen a una verdadera catástrofe personal. Es cierto que, a raíz de esta situación, Figueras decide abandonar el país, con lo que emprende un camino distinto al que sigue el personaje creado por Gutiérrez. Sin embargo, el exilio no se revela como una solución, pues también lo aboca a la pobreza y al desamparo por motivos que él mismo se ocupa de consignar:

Un día [...] salí de Cuba y llegué al gran país americano. Aquí me esperaban unos parientes que nada sabían de mi vida, y que después de veinte años de separación ya ni me conocían. Creyeron que llegaría un futuro triunfador, un futuro comerciante, un futuro playboy; un futuro padre de familia que tendría una futura casa llena de hijos [...]; y lo que apareció en el aeropuerto [...] fue un tipo enloquecido, casi sin dientes, flaco y asustado, al que hubo que ingresar ese mismo día en una sala psiquiátrica [...]. Una vergüenza. Una mancha terrible en esta familia de pequeños burgueses cubanos [...] poseedores de magníficos autos de último tipo y casas de amplios cuartos con aire acondicionado y calefacción, donde no falta nada en la despensa. Ese día (el de mi llegada), sé que se miraron todos con vergüenza, hicieron algún comentario mordaz, y salieron en sus autos del aeropuerto con la idea de no verme jamás. (Rosales 14)

Este pasaje demuestra que, tal como sucede en Trilogía, unas circunstancias históricas determinadas favorecen la inmersión del protagonista en el mundo de los parias. No obstante, para llegar al fondo de esta idea, resulta imprescindible que nos detengamos a considerar el hecho de que Figueras se constituye en una especie de arquetipo, pues sus vivencias representan las dificultades enfrentadas por los cubanos que abandonaron la Isla a principios de los años 80 para radicarse en los Estados Unidos.

Muchos de estos exiliados no lograron encajar en un modelo socioeconómico teóricamente opuesto al que imperaba en su patria. Habituados a 
los esquemas del socialismo, carecían de las herramientas necesarias para desenvolverse adecuadamente en un sistema capitalista, algo que, con frecuencia, los abocó a la pobreza y a la exclusión. En consecuencia, lejos de participar del sueño americano, comprobaron que la democracia liberal estadounidense también imponía normas férreas de conducta y pensamiento, rechazando a todos aquellos que no cumplieran con las mismas. Por si esto fuera poco, no contaron con el apoyo de la comunidad cubana afincada en Estados Unidos desde los tiempos de la Revolución. Varios miembros de este colectivo habían conseguido labrarse una existencia cómoda, respetable y adaptada a las costumbres imperantes en el país de acogida por lo que, a menudo, renegaron de unos compatriotas que llegaron en pésimas condiciones y que no se ajustaban en absoluto a los valores que ellos pretendían encarnar.

Todas estas realidades gravitan sobre el fragmento de Boarding home citado arriba, de forma que se nos revela cómo el hundimiento de Figueras en la marginación posee un claro trasfondo histórico ${ }^{6}$. En este sentido, tampoco resulta casual que el personaje comience su relato de la siguiente manera:

La casa decía por fuera "boarding home”, pero yo sabía que sería mi tumba. Era uno de esos refugios marginales a donde va la gente desahuciada por la vida. Locos en su mayoría. Aunque, a veces, hay

${ }^{6}$ Las cuestiones abordadas deben relacionarse con un episodio que tuvo lugar entre el 15 de abril y el 31 de octubre de 1980: el denominado Éxodo del Mariel. En esta localidad cubana se halla el puerto a través del cual el gobierno castrista decidió autorizar la salida de todos aquellos que no desearan permanecer en la Isla. Se calcula que, entonces, unos 125.000 ciudadanos partieron hacia Estados Unidos, lo que generó una auténtica crisis migratoria. Entre los exiliados, se encontraban escritores como Reinaldo Arenas, Roberto Valero, Carlos Victoria o Juan Abreu, quienes reflejaron en sus obras las situaciones dramáticas encaradas por los llamados marielitos. Suele agruparse a estos escritores bajo el rótulo de Generación del Mariel, pues todos comparten un rasgo esencial que Arturo Matute Castro explica del siguiente modo: "[Sus textos] representan el drama de un sujeto atrapado dentro de un limbo de opciones políticas, morales, intelectuales y de subsistencia $[\ldots]$ que conducen hacia distintos derroteros personales, ninguno de los cuales le satisfacen íntegramente o lo convencen en el plano ético. Esta constituye, por tanto, una literatura de damnificados por los dos grandes modelos sociales y políticos del pasado siglo en sus variantes específicas del socialismo cubano y la sociedad de consumo norteamericana" (87). Guillermo Rosales no participó en el Éxodo del Mariel, dado que se trasladó a Miami desde España en enero de 1980; pero, sin duda, aborda los mismos temas que señala Matute Castro. 
también ancianos dejados por sus familias para que mueran de soledad y no jodan la vida de los triunfadores.

-Aquí estarás bien - dice mi tía sentada al volante de su Chevrolet último modelo-. Comprenderás que ya nada más se puede hacer. (Rosales 11)

El narrador, en efecto, se muestra comprensivo con la mujer que ha decidido recluirlo en un hospicio inmundo, de modo que dice:

Casi estoy por agradecerle que me haya encontrado este tugurio para seguir viviendo y no tener que dormir por ahí, en bancos y parques, lleno de costras de mugre y cargando bultos de ropa. [...] La entiendo. He estado ingresado en más de tres salas de locos desde que estoy aquí, en la ciudad de Miami, a donde llegué hace seis meses huyendo de la cultura, la música, la literatura, la televisión, los eventos deportivos, la historia y la filosofía de la isla de Cuba. No soy un exiliado político. Soy un exiliado total. (Rosales 11)

Figueras acepta su destino porque se reconoce ya como un paria; es decir, como alguien condenado a llevar una existencia ignominiosa, marcada por la sordidez y las penurias. Pedro Juan muestra una actitud similar a esta desde el primer relato que aparece en Trilogía, donde comenta lo siguiente:

Ya me estaba [...] acostumbrando a la miseria. Empezó a llover y a tronar, con un viento de ciclón y una humedad terrible. [...] Me acosté a dormir. Estaba sudado y las sábanas sucias, pero me gusta mi olor a sudor y suciedad. [...] Creo que me quedé dormido. Si el viento arreciaba más y arrancaba las planchas de fibrocemento del techo me daba igual. Nada importa. (Gutiérrez 11-12) 
Los personajes deciden afrontar sin reserva alguna todo lo que implica caer en la marginalidad, determinación que engendra una de sus características distintivas. Un segundo rasgo que ambos comparten viene dado por el hecho de que no renuncian a su condición de escritores, sino que optan por redefinirla de acuerdo con los nuevos espacios donde se radican. Así las cosas, adquieren una identidad muy peculiar que, sin duda, establece un diálogo con las teorías acerca de la intelligentsia paria que revisé antes, pero que no se agota en el marco de estas, razón por la que me gustaría valerme de un concepto más para estudiar su caso: la noción de lumpen forjada por Karl Marx y Friedrich Engels.

En el Manifiesto comunista, los pensadores alemanes sostienen que el lumpenproletariat, o 'proletariado andrajoso', constituye un "producto pasivo de la putrefacción de las capas más bajas de la vieja sociedad" (Marx y Engels 35). Esta definición nos indica que la referencia a los harapos encierra un claro valor simbólico, pues más que hacer hincapié en el aspecto externo de unos sujetos que no disponen de los recursos económicos necesarios para vestir dignamente, persigue designar una carencia profunda, de naturaleza metafísica.

Marx y Engels opinan que el lumpen lo conforman seres humanos cuya miseria y degradación se explican no por unas determinadas circunstancias materiales, sino por una especie de tara congénita. Se trata, así, de tipos esencialmente perversos, que siempre apuestan por la vileza debido a su incapacidad para desarrollar y asumir cualquier valor moral o ideológico. Comprendemos, entonces, que a lo largo de sus escritos ambos describan a este grupo empleando términos y expresiones como "masa informe, difusa y errante", "hez", "desecho" (Marx, El 18 Brumario n.p.) o "escoria integrada por los elementos desmoralizados de todas las capas sociales" (Engels n.p.). Por tanto, nos hablan de un vertedero donde se congregan todos aquellos individuos que, a su juicio y tal como observa Gertrude Himmelfarb, no poseen "un lugar legítimo en la sociedad" ni "un papel [...] en la historia" (457).

Partiendo de aquí, Marx señala los rasgos que distinguen al lumpen en tanto versión corrompida de las clases pobres y trabajadoras. Ante todo plantea que, 
CATEDRAL Tomada: Revista de crítica literaria latinoamericana / Journal of Latin American Literary Criticism

"Con los pobres de la tierra quiero yo mi suerte echar...": la figura del intelectual-lumpen en las obras de Guillermo Rosales y Pedro Juan Gutiérrez

debido a su inmoralidad y a su rechazo de las ideologías, los miembros de este colectivo se preocupan, únicamente, por encontrar formas expeditivas de sobrevivir. En consecuencia, suelen actuar como parásitos, pues su "ciencia financiera" se reduce al principio de "obtener dinero regalado y prestado" (Marx, El 18 Brumario n.p.), de forma que procuran "enriquecerse, no mediante la producción, sino mediante el escamoteo de la riqueza ajena ya creada" (Marx, "Las luchas" n.p.). A esto se une, según el autor de El capital, un "desenfreno por la satisfacción de los apetitos [...] malsanos y desordenados" (Marx, "Las luchas" n.p.); es decir, un afán incontrolable por complacer, muchas veces a través de medios ignominiosos, las demandas de los impulsos más primarios y elementales.

Teniendo en cuenta lo dicho, cabe afirmar que el concepto de abyección gravita sobre las teorías elaboradas por Marx y Engels. Como explicó magistralmente Julia Kristeva, el sujeto racional crea esta noción para designar lo que le produce asco y rechazo. Por ello la aplica, en primer término, a las manifestaciones perceptibles de la suciedad y el desecho, entre las que se incluyen los fluidos corporales y ciertos procesos fisiológicos como defecar, morir, copular, envejecer o menstruar. Pero la categoría de lo abyecto posee un radio de acción más extenso ya que, según Kristeva, permite a las sociedades ubicar en el "linde de la inexistencia" todo aquello que, de ser reconocido, podría aniquilar sus valores y costumbres (8); es decir, también sirve para tachar de perniciosos y repulsivos a sujetos, grupos humanos o modos de vida que no encajan en unas determinadas fórmulas culturales e ideológicas. Tomando como referencia estos principios, entendemos mejor la forma en que Marx y Engels presentan al lumpen: los filósofos entienden que palabras como escoria o podredumbre resultan las más adecuadas para describir la identidad y el hábitat natural de un colectivo que permanece ajeno a los modelos de conducta y pensamiento adoptados por las distintas clases sociales.

Estas ideas parecen definir la realidad que Pedro Juan y Figueras asumen como propia y de la que ofrecen una exhaustiva descripción en sus relatos. Para empezar, ambos se mueven por espacios sórdidos y precarios, lugares que, en el caso del primero, emergen a lo largo de todo el barrio donde reside, Centro Habana. 
Así, el narrador de Trilogía nos muestra cómo, debido a los graves problemas económicos que sufre Cuba, este distrito se ha transformado en un territorio idóneo para el florecimiento de la miseria y, por consiguiente, en un hogar para el lumpen. Esta situación se expone de una manera clara en el siguiente fragmento de la obra:

El barrio [...] se llenó de gente vulgar, venida de provincias, [...] de gente mal vestida, sucia, mal educada. Los edificios se arruinaron por la falta de cuidados y poco a poco se convirtieron en cuarterías con miles de personas hacinadas como cucarachas. Personas delgadas, mal alimentadas, sucias, sin empleo, tomando ron a todas horas, fumando mariguana, tocando tambor, reproduciéndose como conejos. (Gutiérrez 295-296)

Por su parte, Figueras se centra en el microcosmos de una casa destinada, según él, a "recoger la escoria de la vida" (Rosales 12). De acuerdo con su condición, los habitantes del refugio mugriento e infame se encuentran sumidos en la ignominia, tal como prueba este pasaje de la novela:

El baño está inundado. Alguien ha metido en la taza un jacket de cuero. El suelo está lleno de heces [...]. Salgo en dirección al otro baño [...]. Allí están todos esperando [...]. Louie, el americano, está dentro del baño hace una hora y no quiere salir. [...] Entonces Pepe [...] lanza un grito atroz, se baja el pantalón, y defeca allí mismo, en el pasillo, a la vista de todos. [...] Eddy [...] se lanza con todo su cuerpo sobre la puerta del baño y la abre [...]. Louie aúlla como un animal acorralado. Se pone el pantalón rápidamente, y se lanza sobre Eddy propinándole una tremenda trompada en la boca. Eddy cae al suelo con la boca ensangrentada. (Rosales 58)

Como vemos, los personajes retratados por Figueras y Pedro Juan dejan a un lado el civismo y las normas éticas para concentrarse en la satisfacción de sus instintos primarios. En consecuencia, se revelan marcados por otro de los rasgos 
CATEDRAL TOMADA: Revista de crítica literaria latinoamericana / Journal of Latin American Literary Criticism

“Con los pobres de la tierra quiero yo mi suerte echar...": la figura del intelectual-lumpen en las obras de Guillermo Rosales y Pedro Juan Gutiérrez

que Marx y Engels consideran típicos del lumpen, algo que el protagonista de Trilogía expone de una manera ejemplar cuando dice:

El pobre [...] no puede complicar demasiado su moral, ni ser muy exigente con su dignidad [...]. "Si me da un poco ya es bueno y lo amo", eso es todo. [...] Bueno, ese instinto de conservación bien desarrollado es una de las caras de la pobreza. Pero la pobreza tiene muchas caras. Quizás su cara más visible es que te despoja de la grandeza de espíritu. $\mathrm{O}$ al menos de la amplitud de espíritu. Te convierte en un tipo ruin, miserable, calculador. [...] Y al carajo la generosidad, la solidaridad, la amabilidad y el pacifismo. (Gutiérrez 153)

En Trilogía aparecen numerosos tipos que responden a estas ideas, ya que sus medios básicos de subsistencia pasan, o bien por lo que Marx define como el "escamoteo de la riqueza ajena" (Marx, "Las luchas" n.p.) - estafa, mendicidad y proxenetismo-, o bien por la comisión de actos delictivos -robo y negocios ilegales- ${ }^{7}$. En cuanto a Boarding home, Figueras muestra cómo los habitantes del hospicio se conforman con recibir un trato indigno a cambio de tener cubiertas sus necesidades más elementales; de ahí que no se rebelen contra el dueño y el supervisor del establecimiento, dos hombres perversos que los someten a toda clase de vejaciones ${ }^{8}$. Por añadidura, y tal como observamos en el pasaje de la novela

${ }^{7}$ Un buen ejemplo a este respecto lo encontramos en el cuento "Los caníbales", donde Pedro Juan relata cómo un hombre llamado Baldomero, que trabaja en la morgue, consigue reunir una pequeña fortuna vendiendo a la hambrienta población supuestos hígados de cerdo que, en realidad, proceden de cadáveres humanos (Gutiérrez 323-330).

${ }^{8}$ Esta situación se refleja con claridad en el siguiente fragmento de la obra: "El boarding home tiene doce cuartos pequeñísimos, y en cada cuarto hay dos camas. [...] Hay tres baños, pero uno de ellos (el mejor) es del jefe, el señor Curbelo. Los otros dos tienen siempre los inodoros tupidos, pues algunos de los huéspedes meten en ellos camisas viejas, sábanas, cortinas y otros artículos de tela que usan para limpiarse el trasero. El señor Curbelo no da papel higiénico. Aunque por ley debía darlo. Hay un comedor, afuera de la casa, que atiende una mulata cubana, llena de collares y brazaletes religiosos, que se llama Caridad. Pero ella no cocina. Si ella cocinara, el señor Curbelo tendría que pagarle treinta dólares más a la semana. Y eso es algo que el señor Curbelo nunca hará. De modo que el mismo Curbelo, con su carota de burgués, es el que hace el potaje todos los días. Lo cocina de la manera más sencilla; cogiendo con la mano un puñado de chícharos o lentejas y 
citado arriba, estos personajes se mimetizan con un ambiente donde la abyección impone su ley, incurriendo ellos mismos en toda clase de comportamientos infames o degradantes.

Lo dicho hasta ahora podría llevarnos a concluir que Figueras y Pedro Juan comparten las nociones acerca del lumpen enarboladas por Marx y Engels. Sin embargo, considero que, más bien, ambos personajes se aplican a contradecir los fundamentos básicos de las teorías que mantuvieron los filósofos alemanes, idea que procuraré desarrollar a continuación.

Ante todo, resulta crucial el hecho de que los dos se integren en este grupo humano, adoptando los rasgos y hábitos del mismo. El cuento de Trilogía "Amores fulminantes" ilustra bien lo que acabo de señalar pues, en él, Pedro Juan declara su adhesión al materialismo característico del lumpen: "Adquirí la costumbre de aprovecharme de todos y de todo. Un cabrón sentido pragmático de la vida. Me la paso sacando cuentas. Calculando cuánto entrego y cuánto me dan a cambio" (Gutiérrez 65).

También cabe citar aquí un pasaje de "Coger el toro por las astas" donde el protagonista aparece mendigando y, además, nos explica con todo detalle las destrezas necesarias para el ejercicio adecuado de esta actividad:

Extendí la mano y comencé a pedirles a todos los que pasaban a mi lado. Apenas les balbuceaba algo. Si pides limosnas no puedes hablar claro, ni razonar, ni nada. Eres un miserable animal, un microbio pidiendo unas monedas por amor de Dios. [...] Es todo un arte pedir limosnas y aparentar imbecilidad, cretinismo, borrachera crónica, estupidez. (Gutiérrez 194)

metiéndolos (¡plaf!) en una olla a presión. Quizás le echa un poco de ajo en polvo. Lo otro, el arroz y el plato fuerte, viene de una cantina a domicilio llamada «Sazón», cuyos dueños, como saben que se trata de una casa de locos, escogen lo peor del repertorio y lo mandan de cualquier manera en dos grandes cazuelas grasientas. Debían enviar comida para veintitrés, pero sólo mandan comida para once. El señor Curbelo considera que es bastante. Y nadie protesta" (Rosales 15-16). 
CATEDRAL TomAda: Revista de crítica literaria latinoamericana / Journal of Latin American Literary Criticism

"Con los pobres de la tierra quiero yo mi suerte echar...": la figura del intelectual-lumpen en las obras de Guillermo Rosales y Pedro Juan Gutiérrez

Al emplear la palabra "arte", el narrador sugiere que, tal como defienden Weber y Scott, los marginados crean unos recursos y unos códigos simbólicos propios, adecuados tanto a su entorno como a sus necesidades. En este sentido, además, las reflexiones de Pedro Juan parecen confirmar los planteamientos del antropólogo estadounidense Oscar Lewis, quien afirma lo siguiente: "The culture of poverty is not just a matter of deprivation or disorganization, a term signifying the absence of something. It is a culture in the traditional anthropological sense in that it provides human beings with a design for living, with a ready-made set of solutions for human problems, and so serves a significant adaptive function" (19).

Por su parte, Figueras abraza las pautas de comportamiento que rigen en el boarding home, de modo que abusa sexualmente de Francis, una enferma mental (Rosales 47-48), e intenta robar a su compañero de cuarto (Rosales 74). Con esto, la degradación del personaje va en aumento hasta culminar en la terrible escena con que cierra su relato:

Me pongo de pie. En un rincón de la sala, Reyes, el tuerto, orina largamente. Arsenio llega hasta a él y se quita el cinturón. Con la hebilla, da un violento cintarazo sobre la espalda del tuerto. Llego hasta Arsenio y le quito el cinturón de las manos. Lo levanto sobre mi cabeza y lo dejo caer, con todas mis fuerzas, sobre el cuerpo esquelético del viejo tuerto. (Rosales 99-100)

Lo expuesto nos permite concluir que, a diferencia de Marx y Engels, estos dos individuos no contemplan el mundo del lumpen desde fuera, como una realidad extraña que se torna censurable porque desafía las propias convicciones; bien al contrario, ambos interiorizan sin reparos las formas de conducta que imperan en las periferias del orden establecido. En su análisis de Trilogía, Amir Valle comenta que este hecho genera una de las facetas más interesantes de la obra en tanto estudio de la marginalidad y plantea unas conclusiones que también resultan aplicables en el caso de Boarding home: "No hay juicios, no hay rechazo; se es así porque no 
existe otro modo de ser, porque la vida no cambiará, aunque algunos lo sueñan" (n.p.).

Las palabras de Valle nos servirán para introducir otro aspecto clave del discurso que articulan Figueras y Pedro Juan. Sin duda, estos personajes consideran que los parias no tienen más remedio que vivir y actuar como lo hacen; pero, al tiempo, muestran cómo las costumbres del lumpen vienen dadas no por un fatum ineludible, sino por una serie de circunstancias políticas y socioeconómicas.

Los espacios y personajes que aparecen en Trilogía deben su carácter abyecto a unos problemas determinados que el narrador de la obra subraya continuamente, insistiendo en la terrible paradoja que han engendrado los abusos y las incongruencias del socialismo cubano. La Revolución se autodefinió como un proceso benefactor que restablecería la dignidad del pueblo, ultrajado por la dictadura y el capitalismo. Sin embargo, esta utopía da paso a un gobierno autoritario que comete serios errores a la hora de encarar la crisis económica de los años 90 y que parece más interesado en defender sus principios ideológicos que en combatir los efectos del colapso financiero ${ }^{9}$. Así las cosas, muchos ciudadanos se verán lanzados a una incesante batalla por la supervivencia diaria, situación sobre la que Pedro Juan reflexiona de una manera ejemplar en este pasaje del cuento "Sabor a mí": "En Centro Habana la gente vive del aire. Nadie tiene dólares y la gente ya se acostumbró a vivir con agua, azúcar, ron y tabaco, y mucho tambor. [...] Mientras estamos vivos hay que seguir pa'lante como sea. Luchas por la vida porque la muerte está segura" (Gutiérrez 264).

${ }^{9}$ Estas ideas, que gravitan sobre un número significativo de los relatos que conforman Trilogía, se corresponden en parte con las mantenidas por especialistas que, desde el ámbito de disciplinas como la historiografía o las ciencias económicas, han examinado los fenómenos acontecidos en Cuba durante las últimas décadas del siglo XX. A este respecto, destaco los siguientes trabajos: Breve historia económica de la Cuba socialista (1994) y "Problemas sociales y económicos en Cuba durante la crisis y la recuperación" (2005) de Carmelo Mesa-Lago, "¿Comienza una transición hacia el autoritarismo en Cuba?” (1997) de Jorge Domínguez y “Entre la Revolución y la Reforma" (1997) de Rafael Rojas. 
CATEDRAL TomAdA: Revista de crítica literaria latinoamericana / Journal of Latin American Literary Criticism

"Con los pobres de la tierra quiero yo mi suerte echar...": la figura del intelectual-lumpen en las obras de Guillermo Rosales y Pedro Juan Gutiérrez

También conviene citar aquí un fragmento del relato titulado "Morboso, muy morboso", donde el personaje se refiere al estado lamentable en que se hallan tanto él como muchos de sus compatriotas:

Por la tarde no tenía nada que hacer. Bueno, así es la cosa día tras día. Nunca se hace nada. Me quedaban cinco pesos en el bolsillo y me senté en el piso, recostado al borde de la puerta. Llevaba días sin darme un trago, sin dinero, esperando. ¿Esperando qué? Nada, esperando. Aquí todos esperan. Un día detrás del otro. Nadie sabe qué espera. Los días pasan. Y el cerebro se embota. Eso es bueno. Tener el cerebro embotado para no pensar. [...] Alguna vez estudié, fui disciplinado, tuve objetivos para mañana y para el año próximo, y salí a luchar por el mundo. Después todo se hizo sal y agua y caí en esta pocilga. Unos tienen sarna, otros tienen piojos, o ladillas. No hay dinero, ni comida, ni trabajo y cada día vienen más. (Gutiérrez 237)

Cabe decir, entonces, que los lugares y los tipos descritos en Trilogía atestiguan el grave deterioro experimentado por todo un sistema político de forma que, tal como señala Achi Obejas, "without ever acknowledging the revolution, Gutiérrez presents its results with a cold eye: the scarcities, the desperation, the humiliation of a people taught and trained to be avatars of change - The New Mannow exploited and dependent on international charity and personal pity" (2). Estas ideas se plasman a la perfección en el texto "Hijo del caos", donde Pedro Juan recurre a una imagen enormemente sugestiva para mostrarnos en qué se ha convertido la utopía socialista:

A través de la ventana yo veía en el edificio de al lado a la mujer vieja, canosa, quizás un poco abandonada y sucia. Sentada en un balance se mecía furiosamente y cantaba sin pausas y mezclando estrofas de La Internacional, el Himno Nacional, la Marcha del 26 de Julio, el Himno de 
los Alfabetizadores, el de las Milicias, de nuevo La Internacional, y lo repetía todo. A veces se callaba un poco, como para tomar aire, y preguntaba: “¿Quién es el último? ¿No hay último en esta cola? ¿Quién es el último para el pan? Bueno, si no aparece el último, yo soy el uno, ahh, lo siento, estoy preguntando y nadie me responde. Compañeros, ¿quién es el último?" Y de nuevo comenzaba: "No habrá César, ni burgués, ni Dios". (Gutiérrez 106)

En síntesis, los relatos que componen Trilogía ponen de manifiesto cómo la crisis económica de los 90 ha provocado que los rasgos y las conductas del lumpen se extiendan entre grandes sectores de la población cubana. De este modo, parecen constituirse en una dura réplica a las proclamas que lanzara Fidel Castro solo diez años antes:

En todo este hemisferio [...] a pesar de que todavía nos queda lumpen desgraciadamente, a pesar de que todavía nos quedan elementos desclasados, que nos quedan elementos antisociales, somos los que menos elementos antisociales y lumpen tenemos en todo el hemisferio, el país de América donde hay menos índice de robo, a pesar de que hay ladrones, menos índice de crimen, índices ínfimos de droga, no hay prostitución, y no se tolera y está totalmente prohibido el juego. [...] Pero no hay una sociedad con un ambiente moral más sano que el de nuestra sociedad en todo este hemisferio; no hay una sociedad con más valores morales que los que ha alcanzado esta sociedad nuestra al cabo de 21 años de revolución, con un sentido de la justicia, con un sentido del honor, con un sentido de la dignidad, con un aprecio y una admiración por el mérito, por el trabajo, por el sacrificio. (n.p.)

Figueras, por su parte, muestra cómo el sueño americano esconde un lado perverso, ya que conquistarlo puede exigir la práctica de comportamientos 
abiertamente inmorales. En este sentido, desmonta el mito del ciudadano triunfador y respetable, tan importante para la ideología liberal, al indagar en la figura del señor Curbelo, dueño del boarding home:

El señor Curbelo [...] está seguro de que nadie se irá del boarding home y de que él seguirá recibiendo los cheques de trescientos catorce dólares que el gobierno americano envía a cada uno de los locos de su hospicio. Son veintitrés locos; siete mil doscientos veintidós pesos. Más otros tres mil pesos que le llegan de no sé cuál ayuda suplementaria, son diez mil doscientos veintidós pesos al mes. Por eso el señor Curbelo tiene una casa en Coral Gables con todas las de la ley y una finca con caballos de raza. Y por eso se dedica los fines de semana al elegante deporte de la pesca submarina. Por esos sus hijos salen retratados el día de su cumpleaños en el periódico local, y él va a fiestas de sociedad vestido de frac y corbata de lazo. (Rosales 16-17)

Este individuo aparece como un tipo despreciable, una especie de parásito que medra a costa de las miserias ajenas, imagen que cobra aún más fuerza cuando el narrador destaca la situación de abandono en la que se encuentran los habitantes del asilo:

En el boarding home nadie tiene a nadie. La vieja Ida tiene dos hijos en Massachusetts que no quieren saber nada de ella. El silencioso Pino está solo y sin conocidos en este enorme país. René y Pepe, los dos retrasados mentales, no podrían jamás vivir con sus hastiados familiares. Reyes, el viejo tuerto, tiene una hija en Newport que no lo ve hace quince años. (Rosales 16)

Como vemos, Figueras pone de manifiesto el destino al que se ven abocados quienes no encajan en los patrones de una sociedad teóricamente democrática. A 
este respecto, también se torna fundamental el pasaje de la obra en el que nos presenta a sus compañeros del boarding home:

Allí estaban todos. René y Pepe, los dos retardados mentales; Hilda, la vieja decrépita que se orina continuamente en sus vestidos; Pino, un hombre gris y silencioso, que sólo hace que mira al horizonte con semblante duro; Reyes, un viejo tuerto, cuyo ojo de cristal supura continuamente un agua amarilla; Ida, la gran dama venida a menos; Louie, un yanqui fuerte de piel cetrina, que aúlla constantemente como un lobo enloquecido; Pedro, un indio viejo, quizás peruano, testigo silencioso de la maldad del mundo; Tato, el homosexual; Napoleón, el enano; y Castaño, un viejo de noventa años que sólo sabe gritar: "iQuiero morir! ¿Quiero morir! ¡Quiero morir!” (Rosales 12)

Descubrimos, entonces, que el hospicio mugriento donde transcurre la novela se convierte en una encarnación de los espacios en los que un sistema capitalista confina a las personas que, de acuerdo con sus parámetros, resultan indeseables. En este sentido, Ivette Leyva Martínez observa que "el home no es hogar sino infierno", pues se constituye en "un círculo demencial donde los infortunados están condenados a reproducir [...] los estadios del ciclo de vida animal" y a ser víctimas de continuas "humillaciones" (99). Así pues, se constata que las formas de vida y pensamiento vigentes en Estados Unidos generan tanto ciudadanos de pleno derecho como individuos condenados al ostracismo, que carecen de visibilidad. Figueras da buena cuenta de este hecho al describir uno de sus paseos por la ciudad de Miami:

Voy a la calle, donde están los triunfadores. La calle, llena de autos grandes y veloces, con las ventanas cerradas por gruesos cristales ahumados para que los vagabundos como yo no puedan fisgonear. Al pasar junto a un café, oigo que me gritan: 
CATEDRAL TOMADA: Revista de crítica literaria latinoamericana / Journal of Latin American Literary Criticism

"Con los pobres de la tierra quiero yo mi suerte echar...": la figura del intelectual-lumpen en las obras de Guillermo Rosales y Pedro Juan Gutiérrez

-¡Loco!

Me vuelvo con rapidez. Pero nadie me está mirando. Los clientes beben en silencio sus refrescos, compran cigarros, hojean el periódico. Comprendo que es la voz que oigo desde hace quince años. [...] La voz que viene de un lugar desconocido, pero muy cercano. [...] Avanzo. ¿Hacia el norte? ¿El sur? ¿Qué más da! Avanzo. Y al avanzar veo mi cuerpo reflejado en las vidrieras de los comercios. Mi cuerpo enteco. Mi boca estropeada. Mi ropa sucia y elemental. Avanzo. En una esquina hay dos mujeres testigos de Jehová que venden la revista Despertar. Abordan a todo el mundo, pero a mí me dejan pasar sin dirigirme la palabra. El Reino no se hizo para los desarrapados como yo. Avanzo. Alguien se ríe a mis espaldas y vuelvo la cabeza enfurecido. No es conmigo. Es una vieja celebrando a un recién nacido. (Rosales 30-31)

Lo dicho nos permite corroborar la idea de que Figueras y Pedro Juan enmiendan las teorías acerca del lumpen planteadas por Marx y Engels. Los filósofos alemanes sostienen que en este grupo humano se congregan sujetos esencialmente viles y degenerados, que no merecen ninguna consideración. Frente a ellos, los protagonistas de Trilogía y Boarding home perciben una característica inherente al submundo de los parias que Christian León explica de la siguiente manera: "Si las instituciones fundan su discurso racional y universalista a partir de la segregación de ciertas colectividades marginales, estas replican el discurso institucional transformándose en su imagen traumática. [...] El espacio marginal [...] muestra la fragilidad de las instituciones y contratos sociales [...]" (13).

Ambos personajes descubren la capacidad de los territorios excéntricos para sacudir las bases del orden establecido porque se integran plenamente en ellos; y, además, logran sacar a la luz todo lo que conlleva este rasgo haciendo uso de las competencias que les otorga su condición de escritores. Por todas estas razones, entiendo que la etiqueta de intelectual-lumpen resulta adecuada para definirlos, si bien es cierto que, igualmente, muestran facetas propias de la intelligentsia paria. 
En lo que se refiere a este último punto, las narraciones de Pedro Juan y Figueras pueden verse como productos simbólicos creados por unos outsiders que plasman los errores y las carencias achacables a dos grandes modelos socioeconómicos: el comunismo y la democracia capitalista. Sus obras, entonces, comportan una rebelión contra estos sistemas emprendida por quienes no disponen de otras armas que las palabras. El protagonista de Trilogía parece admitir este hecho cuando dice lo siguiente: "Ya no podía seguir en silencio, escribiendo tonterías a cambio de algún halago. El juego tenía reglas demasiado estrictas. Sólo se podía decir 'sí'. Y no merecía la pena. Lo mandé todo al carajo y escribía unos relatos desnudos. Mis relatos podían salir en cueros por el medio de la calle, gritando: ¡Libertad, libertad, libertad!” (Gutiérrez 85-86). Asimismo, el estudio del lumpen que llevan a cabo estos dos personajes adquiere una evidente fuerza subversiva desde el momento en que nos invita a cuestionar unas estructuras de poder que engendran graves injusticias, por lo cual resulta factible entender que nos hallamos ante una manifestación de lo que Scott denomina "infrapolítica".

Para terminar, quisiera añadir que Pedro Juan y Figueras se presentan como los alter ego literarios de sus respectivos creadores, pues las experiencias que los sumen en la marginalidad coinciden, en gran parte, con situaciones vividas por Gutiérrez y Rosales. Por ello, cabría decir que, en cierto modo, la figura del intelectual-lumpen también les sirve para ejecutar una venganza simbólica, dirigida contra los sujetos y las instituciones que los condenaron al ostracismo. Al tiempo, sin embargo, tanto ellos como sus personajes asumen un profundo compromiso ético, descrito por Gutiérrez en una sencilla frase con la que me gustaría cerrar estas reflexiones: "Puede parecer un poco petulante esto, pero de algún modo, yo soy como la voz de los que no tienen voz" (Franco n.p.). 
CATEDRAL TOMADA: Revista de crítica literaria latinoamericana / Journal of Latin American Literary Criticism

“Con los pobres de la tierra quiero yo mi suerte echar...": la figura del intelectual-lumpen en las obras de Guillermo Rosales y Pedro Juan Gutiérrez

\section{Bibliografía}

Bajtin, Mijail. La cultura popular en la Edad Media y en el Renacimiento.

Madrid: Alianza Editorial, 1990.

Cardinal, Roger. Outsider Art. Londres: Studio Vista, 1972.

Castro, Fidel. "Discurso pronunciado por el Comandante en Jefe Fidel Castro

Ruz, Primer Secretario del Comité Central del Partido Comunista de Cuba y Presidente de los Consejos de Estado y de Ministros, en el Acto

Conmemorativo del Primero de Mayo, efectuado en la Plaza de la

Revolución 'José Martí', el 1 de Mayo del 1980, ‘Año del Segundo

Congreso"'. Portal Cuba.cu, 1980.

www.cuba.cu/gobierno/discursos/1980/esp/f010580e.html.

. "Palabras a los intelectuales". Revolución, Letras, Arte. La Habana:

Letras Cubanas, 1980, pp. 7-33.

Domínguez, Jorge. “¿Comienza una transición hacia el autoritarismo en Cuba?”.

Encuentro de la Cultura Cubana, 6-7, 1997, pp. 7-23.

Dubufett, Jean. El hombre de la calle ante la obra de arte. Madrid: Debate, 1992.

. Escritos sobre arte. Barcelona: Barral, 1975.

Engels, Friedrich. "Prefacio a La guerra campesina en Alemania". Archivo MarxEngels, 1870. www.marxists.org/espanol/m-e/1870s/1874-pgca.htm.

Fauchereau, Serge (ed.). En torno al art brut. Madrid: Círculo de Bellas Artes, 2007.

Franco, José Javier. "Resistencia y escritura en La Habana”. Aporrea, 2005. www.encontrarte.aporrea.org/19/creadores/a5444.html.

Guevara, Ernesto. El socialismo y el hombre nuevo. México: Siglo Veintiuno, 2003.

Gutiérrez, Pedro Juan. Trilogía sucia de La Habana. Barcelona: Anagrama, 1998.

Himmelfarb, Gertrude. La idea de la pobreza. Inglaterra en los principios de la época industrial. México: Fondo de Cultura Económica, 1988.

Kristeva, Julia. Poderes de la perversión. Buenos Aires: Catálogo, 1988. 
Le Goff, Jacques (coord.). Herejías y sociedades en la Europa preindustrial (Siglos XI-XVIII): comunicaciones y debates del Coloquio de Royaumont. Madrid: Siglo XXI de España, 1987.

León, Christian. El Cine de la Marginalidad. Realismo sucio y violencia urbana. Quito: Universidad Andina Simón Bolívar / Abya-Yala / Corporación Editora Nacional, 2005.

Lewis, Oscar. "The Culture of Poverty". Scientific American, 215, 4, 1966, pp. 19-25.

Leyva Martínez, Ivette. "Guillermo Rosales o la cólera intelectual". Encuentro de la Cultura Cubana, 26-27, 2003, pp. 98-108.

Martín Sevillano, Ana Belén. Cuento cubano actual (1985-2000) (tesis doctoral). Madrid: Universidad Complutense, 2001.

Marx, Karl y Friedrich Engels. Manifiesto comunista. Madrid: Akal, 2007.

Marx, Karl. El 18 Brumario de Luis Bonaparte. Dirección de Educación Uruguay, 1852.

www.edu.mec.gub.uy/biblioteca_digital/libros/m/Marx,\%20Karl\%20\%20Brumario\%20de\%20Luis\%20Bonaparte,\%20El\%2018.pdf. . "Las luchas de clases en Francia de Enero de 1848 a 1850". Marxist Internet Archive, 1850. www.marxists.org/espanol/m-e/1850s/francia/.

Matute Castro, Arturo. "Dos narrativas de Mariel: muestrario de perdedores y suicidas". Mitologias hoy. Revista de pensamiento, critica y estudios literarios latinoamericanos, 12, 2015, pp. 83-100.

Mesa-Lago, Carmelo. Breve historia económica de la Cuba socialista. Madrid: Alianza, 1994.

. "Problemas sociales y económicos en Cuba durante la crisis y la recuperación". Revista de la CEPAL, 86, 2005, pp. 183-205.

Obejas, Achi. "From Havana with Love: A New Generation Faces Cuba's Dark Reality". Village Voice Book Review, 2001, pp. 82-119.

Platón. Diálogos. República. Madrid: Gredos, 1988. 
CATEDRAL TOMADA: Revista de crítica literaria latinoamericana / Journal of Latin American Literary Criticism

“Con los pobres de la tierra quiero yo mi suerte echar...": la figura del intelectual-lumpen en las obras de Guillermo Rosales y Pedro Juan Gutiérrez

Rojas, Rafael. "Entre la Revolución y la Reforma". Encuentro de la Cultura Cubana, 4-5, 1997, pp. 122-136.

Rosales, Guillermo. La casa de los náufragos (Boarding home). Madrid: Siruela, 2003.

Scott, James C. Los dominados y el arte de la resistencia: discursos ocultos.

México: Ediciones Era, 2007.

Thévoz, Michel. L'art brut. Ginebra: Skira, 1995.

Valle, Amir. "Anda un rey en La Habana: Pedro Juan Gutiérrez puede llamarse". Todo sobre Pedro Juan, acceso el 20 de agosto, 2013. www.pedrojuangutierrez.com/Ensayos_ensayos_Amir-Valle.htm.

Weber, Max. Sociología de la religión. Madrid: Akal, 2012. 